plunger, piston or bucket (Fig. 6) though none of these names defines it. A pole four to five feet in length and having a diameter of 1 to $2 \%$ inches is fitted with cross handle like the handle of a gimlet. The othe end of the pole is cut to a smaller diameter for a distance of $1 \frac{1}{2}$ inches from the end, leaving a shoulder. This part of smaller diameter is passed through a hole of equal diameter in the center of a disk of green or thoroughly soaked rawhide. The diameter of this rawhide disk is from six to eight inches, depending upo the diameter of the bore of the tube. To the oute edge of this disk and equally spaced are fastened six rawhide straps about six inches in length and threefourths of an inch in width. These straps are nailed or tied to the pole at such a distance above the shoulde as to allow the soft disk to form a pocket or sack, th outer diameter of which, when expanded by the pressure of the water, will be sufficient to permit a more or less tight fit in the working barrel of the pump tube The flexibility of the plunger allows it to fit all the irregularities of the interior of the palm stalk crudel fashioned as it usually is. Riveted sheet-iron pipes of four, six, or eight inches in diameter may be readil converted into hand pumps by the use of such valve and plungers. The rivet heads inside of the pipes seem to have no effect upon the working efficiency of pumps thus constructed, so great is the adaptability of the fiexible rawhide plungers.

The pumps in their working positions stand at angles from 35 to 50 degrees from the horizontal and raise water from six to eight feet in vertical height. One lift is usually sufficient for plts sunk in the sand bars of the rivers. Where one lift is not sufficient, one side of the pit is cut down and a shelf is formed. The water is raised by one series of pumps from the bottom to the shelf and by another series from the shelf to the surface. As depth is gained and the flow of water increases the pumping keeps pace by increasing the number of pumps. In extreme instances as many as 20 pumps have been used to keep a $12 \times 14$-foot pit free of water. As the work of each pump operator is equal to that of every other, and as the pay is equal, the boss of the pit insists on synchronous movement. If all keep time with the pacemaker no one is loafing.

$$
\text { PARTS OF RIVER CUT OFF BY DAMB. }
$$

The most ambitious of all the native engineering projects for reaching the gold in the river bottoms is known by the name of the tapado. The tapado might be defined as a wing dam that bends back to the bank inclosing and cutting off a part of the river bed. The dam is constructed by driving stakes close together in a double line and filling the space between the lines with clay, well tamped in. The lines of stakes are separated by a space of about four feet. The stakes are fastened together by binding all to horizontal poles placed near the top. These horizontal poles are then bound to cross poles placed about every four or five feet. Vines, bejucos, from the jungle are used for the binding.
Previous to filling in with clay, palm leaves are placed inside and against the stakes. When the tapado has been completed, the water is pumped from behind the dike and mining proceeds. At points near riffles or cascades, the tapado dam may be run out from the bank above, and terminate at a lower level, going down the riffle. If the fall is greater than the depth of the water outside of the upper end of the tapado, the lower end outside of the upper end of the tapado, the lower end
is left open and no pumping is required, as the space inside drains itself.

At most of the large mines on the Porce River, where the playas are being worked by means of hydraulic elevators, the operators take advantage of a protracted dry season to put large tapados into the river, thus making accessible considerable additions to their workable territory. Since the borders of the playas adjacent to the river are almost without exception the richest parts, the areas thus added are highly remunerative. LEABING SYBTEM POPULAR.

The river workers generally consume so much time in building their tapados that little is left of the drv season for the work of getting at the bedrock. Partly for this reason and partly from the fact that the natives find it the usual thing to do, the corte system consists in leasing small cortes, or areas within the mine or tapado, for a percentage of the product. This percentage depends upon the expected total yield and upon the live lines of the competition for the opportunity to work a corte. If the mine or tapado has the reputation of being rich and competition is active, the owner may demand and get as high as 50 to 60 per cent. of the gold produced. On the other hand, he may not be able to secure leasers unless he concedes to them 80 per cent ${ }^{-}$of the product.

W AGES DEPEND ON AMOUNT OF GOLD RECOVERED.

The river workers are always required to pay 20 per cent of their gross washings to the owners of the mines. The river miners have unlimited opportunities for concealing the amounts of gold they actually wash out, and their incessant shifting from one mine to another makes it a hopeless task for the owners to keep track of then. It is safe to say that a portion much smaller

The owners of the tapados keep out the water receive, weigh and sell the gold. The lessees frequently sublet their privileges. The peons sometimes receive their food and lodging only and are promised a proportional division of one half of the gold that falls to the share of the lessee or sublessee after he has paid his percentage. Sometimes the peons prefer to board themselves, particularly if they have families. Since they invariably live from hand to mouth, they must have some pay. In that event their employer contracts to pas them one half of the ruling wage and promises a proportional division of one quarter of his share of the gold to complete their pay.

At other times the peon receives something less than the ruling wage and is promised by his employer a pinta as a final settlement. This is the product of a batea full of gravel taken from the bedrock. On the Porce River, 95 per cent of all the gold is on bedrock or within a foot of it, so this method is sometimes highly satisfactory. The peon is always ready to take a gamble in a small way.

\section{GRAVEL CABRIED FROM THE PITS.}

The operating force for each corte usually consists of one shoveler, rarely more, batea passers, hand-barrow carriers and washers, who wash the gravel and attend to the sluices. The lessee or sublessee generally acts as capitan or boss. Each pair of hand-barrow carriers will carry the loaded barrows a distance of only 25 to 40 feet, depending upon the steepness of the runways. As many as four to seven pairs of carriers are employed for each corte, where the runs are from 200 to 300 feet in length. The transportation of the gravel for such distances is not infrequent at the playa mines, in which the gravel is from $\mathbf{4 0}$ to $\mathbf{5 0}$ feet in depth.

As stated elsewhere, the wages of the peons are higher during the dry seasons, so that the cost for each peon (wages and food) will not be far from 70 cents per day. During the wet seasons plenty of good peons may be employed at a total cost of 50 cents per day each. The hand-barrows as loaded hold from 1 to $11 / 4$ cubic feet. From 3 to 5 cubic yards of gravel are removed from each corte per day at a cost of from 80 cents to $\$ 2$ per cubic yard. It takes good ground to stand such costs and to produce a profit. The corte system has been defined as the one designed to distribute the product of the mine to the greatest number of Colombians.

BEDROCK NEVER THOROUGHLY CLEANED.

Within the last eighteen months the native miners have learned a lesson from the Americans, who are putting in hydraulic elevators for the purpose of working the deeper water-filled gravels of the playas. The depth of the gravels range from 12 to 55 feet. Up to the present, these more progressive miners seem to their elevator equipments are too small to do more tlan serve as pumps and keep the pits fairly clear of water. These water elevators are so far superior to the old-time overshot water wheels used for driving four to six pumps, that the latter are now being but little employed. These ponderous slow-moving contraptions were never more than partially successful and enabled the miners to reach only the highest portions of the bedfock. The same ground formerly mined by natives with the aid of these water-wheel-driven pumps, has since been wáshed by Americans, using hydraulic elevators with most satisfactory returns. The minin done by the Americans developed the fact that the natives of former times had succeeded only in cleanin; up the ridges of the bedrock, whereas the best of the gold was found in the depressions. Thus a rich harvest
was left for those who arrived late upon the scene.

\title{
Economy Due to Superheated Steam in Marine Practice*
}

\author{
Increased Thermal Efficiency Gained Without Additional Cost for Repairs
}

\section{By Walter M. McFarland}

Tre theoretical advantages of the use of superheated steam were evident at an early date, as indeed would be inevitable when the principle of the Carnot heat eycle was understood. In the early days, when materials were not nearly so good as at present, and steam pressures were accordingly much lower, the benefit of getting the conomy due to a very much higher initial temperature with no increase of pressure was, of course, obvious Accordingly, very many experiments were made and a number of plants were installed using superheated steam, often with special superheating boilers. On the whole, often with special superheating boilers. On the whole,
these early installations were not practical successes, on these early installations were not practical successes, on although the heat economy was obtained. In those days workmanship was not so good as now, and the causes of corrosion were not only not properly understood but there was dense ignorance concerning them so that the measures taken to prevent corrosion really increased it. Obviously, there was no commercial increased it. Obviously, there was no commercia economy in a system where the cost of repair
ceeded the saving due to increased economy.

In more recent years, since corrosion has been better understood and the means for preventing it are fairly well known, the attractiveness of the benefit to be derived from superheating has led to its reintroduction, and this article is intended to be a brief discussion, with some illustrative examples, of the economy which comes from the use of superheat.

In land installations, where poppet valves can be

- Reproduced trom International Marine Engineering. used, so that the question of valve friction does not come up, superheat may be used to almost any degree that is desired, and there are a great many examples of such engines on the continent of Europe which are workin with a remarkable degree of economy, in some cases ver closely approaching 1 pound of coal per horse-power hour.

With the steam turbine, where there are no rubbing surfaces, the benefit to be derived from superheat wa at once apparent, and, generally speaking, it may be sajd that all the large power houses and central stations which use steam turbines also use superheat, In these case there is not only the thermal economy due to superheat, but it has been found that the dry steam has much less erosive action on the blades of the turbines than steam which is moist. An excellent article by Capt. C. A Carr, U. S. N., published in the Journal of the American Society of Naval Engineers for February, 1911, gives a great deal of information with respect to these land plants, and will repay very careful study. Speaking generally, it is considered that with steam turbines of modern design and carrying from 175 to 200 pounds of steam pressure, there is a saving in steam consumption of about 1 per cent for each 10 degrees of superheat.

About ten years ago, Capt. Augustus B. Wolvin, then the manager of a number of steamboat lines on the Great Lakes, and who has been one of the pioneers in the adoption of improvements in marine machinery tending to economy, installed Babcock \& Wilcox boilers and superheaters in one of the vessels under his control, and followed this by eimilar installations on several other ves sels. One of these, the "James C. Wallace," was subjected to a test by a board of naval engineer officers, and showed a saving in coal of about 9 per cent, with an average superheat at the engine of about 85 degrees The Bureau of Steam Engineering took up this subject and in 1904 ordered Babcock \& Wilcox boilers and superheaters to replace the old cylindrical boilers on the "Indiana." This was followed by installations of similar boilers and superheaters on the "Massachusetts" and the "New York" (now "Saratoga") in the way of replace ments, and on the "Michigan," "South Carolina," "Prometheus," "Vestal," "Delaware," "North Dakota," "Texas" and "New York" (new), new vessels. In 1905 boilers and superheaters from the same makers were ordered for the steamship "Creole," with respect to whose performance some interesting data will be given later on The Pennsylvania Railroad, in its marine service, has always shown a desire to get the safest and most efficient machinery, and in 1909 ordered from this concern boilers and superheaters for three of their large tugs, the "Johnstown," "Wilmington" and "Harrisburg," which have given great satisfaction and economy in service. The steam yacht "Idalia" also has a boiler and superheater supplied by this same firm.

It will thus be seen that superheat is in use on a large number of vessels, and undoubtedly a great deal of experience has been accumulated, but, unfortunately, not very much has been published.

Table I gives the performance of the steamship "Creole," which is fitted with Babcock \& Wilcox boilers and superheaters, as compared with the performance of 
her two sister ships, the "Momus" and "Antilles," which have ordinary cylindrical boilers without superheat. As shown by the table, the hulls are practically identical. The "Creole" has twin screw engines of about 7,000 horse-power, while the "Momus" and "Antilles" have single screw engines of about 7,500 horse-power. Al three ships carry about the same steam pressure-about 210 pounds. The "Creole" was originally fitted with Curtis turbines, but the speed was too low (151/2 knots) to permit economical use and they were removed. It is to be noted that so far as there is any advantage in engine economy it should be with the "Momus" and "Antilles," which have each a single engine of about th same power as the aggregate of the two engines on the "Creole," thereby reducing the losses due to cylinder condensation. The engines are all triple expansion and of excellent design. The "Creole's" first trip with her new engines was made in the spring of 1910 . Two comparisons are given, one of five round trips of the "Creole" in the summer of 1910, as compared with five round trips of each of the others, obtained by taking their best performances in the three summers of 1908, 1909 and 1910 . The second comparison is between two round trips of all three vessels made in the month of October, 1910. They run over the same route from New York to New Orleans, and, as the hulls are identical and the engines designed and built by the same firm, the only material difference is in the boilers and superheat. The table shows that the "Creole" operates with about 17 per cent less fuel per round trip than her sister ships. The average superheat carried is about 60 degrees, from which a saving of about 6 per cent would be expected. It is to be noted however, that there is a distinct gain in economy due to the use of the Babcock \& Wilcox boiler, as contrasted with the cylindrical or Scotch boiler.

In an article by the late Admiral George W. Melville U. S. N., published in the Engineering Magazine for January, 1912, are given reports of very accurate tests of Scotch boilers and of Babcock \& Wilcox boilers, made by boards of navy officers and committees of independent engineers, so that the reliability of the data is beyond

Table II.-Economy Due to Superheated Steam.

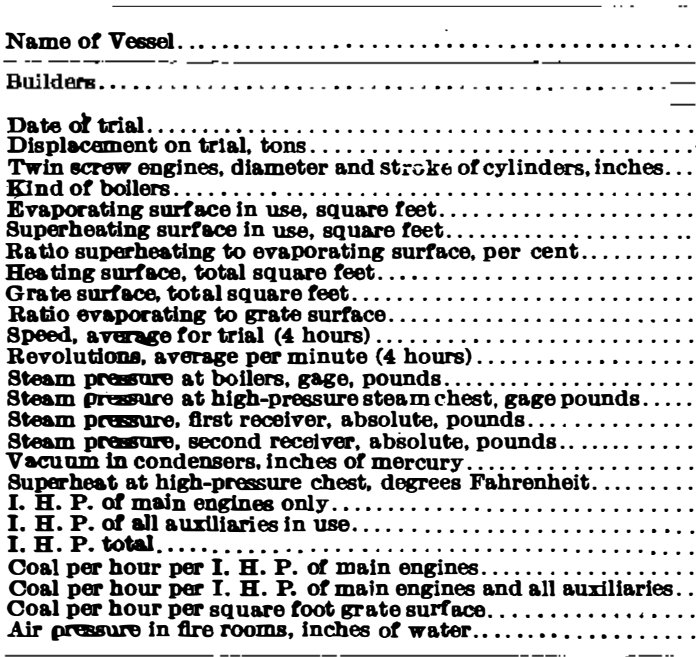

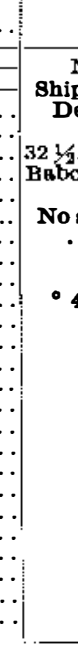

question. These tests showed that, at the rate of combustion obtaining in these vessels, the Babcock \& Wilcox boiler shows an efficiency of about 74 per cent, as against from 62 to 67 per cent (average 64.5 per cent) for th Scotch boiler. Working out the saving due to this greater efficiency, it comes to 11.7 per cent, and this substracted from 17.45 per cent,' the total saving, leave 5.75 per cent as the saving due to superheat, which agrees quite well with the rough general rule of 1 per cent saving for each 10 degrees of superheat.

Table II gives the performance of four United State navy vessels, all of the same displacement and approximately the same power, and all fitted with Babcock \& Wilcox boilers. The "Kansas" and the "New Hampshire" have no superheaters, while the "Michigan" and the "South Carolina" are fitted with superheaters. The performance of these four ships is very interesting, showing a saving, based on the average of the two ships, with superheaters as contrasted with the two without, of 18.52 per cent. In this connection it is interesting to note th remarks of Commander Henry C. Dinger, U. S. N formerly editor of the Journal of the American Society of Naval Engineers, who wrote the account of the trial of the "South Carolina," and who says with respect to the better performance of the ships with superheaters:

"The engines of the "Michigan" and "South Carolina" represent a decided advance in economy of steam consumption of navy reciprocating engines. The design embodies the use of (1) superheated steam; (2) large ratio'of cylinders, namely, $\frac{H . P .}{L . P .}=\frac{1}{10}$, and (3) a considerable reduction of cylinder clearance. Calculations from indicator cards indicate that the steam consumption at full power was about 12.6 pounds of water per
indicated horse-power. This result may be considered

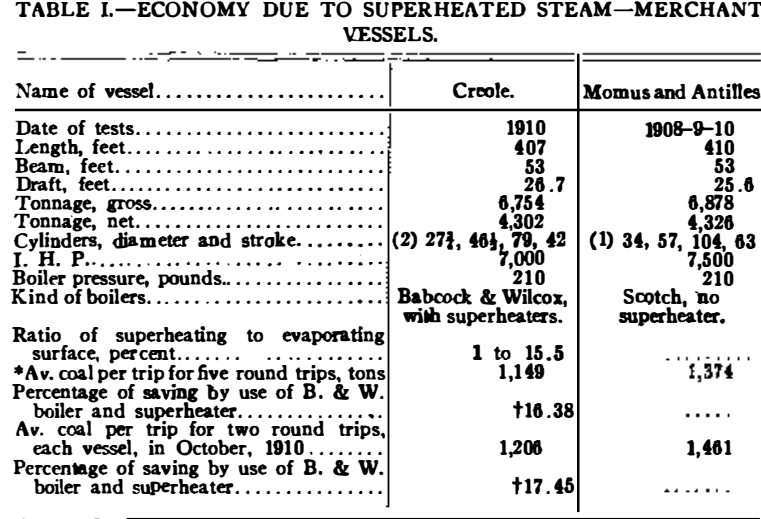

* The "Creole's trips were in summer of 1910; those of the 1908 , '09 and ' 10.

†The Improved economy is due partly to greater effelency
of boiler of "Creole" and partly to superheat. See text for of boller of "Creole" and partly to superheat. See text for

as being within a few per cent of the actual consumption. This shows a gain of about 16 per cent over previous navy practice; of this gain one half may be assigned to the use of superheated steam, and the other due to reduction of clearance and better cylinder proportions."

In October, 1909, a test was made of the machinery of the yacht "Idalia" with superheated steam by Dr. D. S. Jacobus, and witnessed and reported by Lieut. John Halligan, Jr., U. S. N. The owner of the "Idalia" is an accomplished engineer, which insures the maintenance of the machinery in first-class condition at all times. She has a four-cylinder triple-expansion engine, the cylinder diameters being 11.5 inches, 19 inches, (2) 22.7 inches by 18 inches stroke. All the cylinders are unjacketed and have piston valves. There is one Babcock \& Wilcox boiler, with 65 square feet of grate surface and 2,500 square feet of evaporating surface and 340 square feet of superheating surface. These tests are notable from the fact that the weight of the steam used was carefully determined by weighing the steam condensed in tanks on

Official Trials of United States Naval Vegsels.

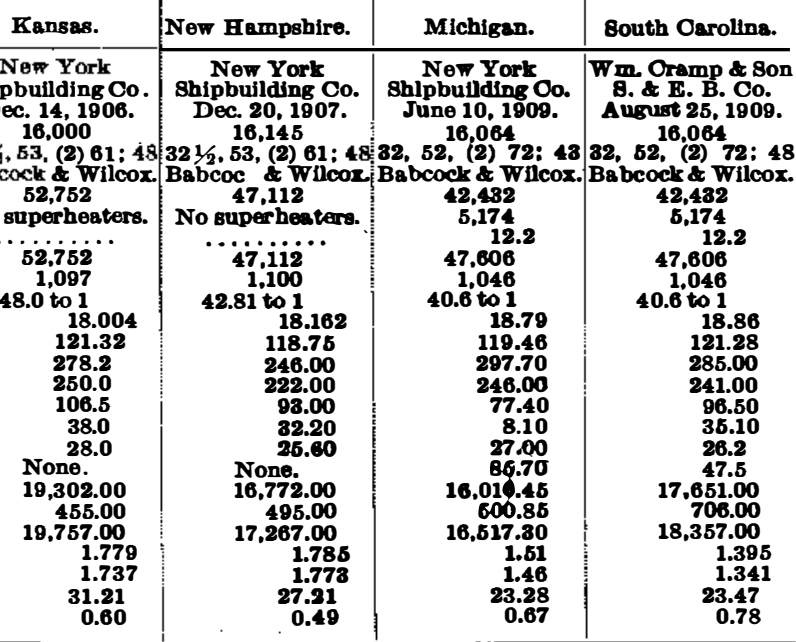

carefully standardized platform scales. The actual duration of the test in each case was about $21 / 2$ to 3 hours, but observations were made every 15 minutes. The well-known reputation of Dr. Jacobus as an experimenter insures the accuracy of the results, which are given in Table III. The duration of the experiments was obviously too short to make it worth while to attempt to measure the coal. It is to be noted that the feed, air and circulating pumps, all of which are independent, discharge their exhaust steam into the main condenser, so that the figures given for steam per horse-power include the steam used by these auxiliaries, as well as by the main engine, while the horse-power is of the main engine only. This is mentioned in order that the results, which might otherwise be considered rather high, may be thoroughly understood.

We have now given such experimental data as are available of measurements of coal and water to show the conomy of superheating, and, as stated above. they bear out the rough rule that there is about 1 per cent in saving f fuel for each 10 degrees of superheat

The practical effect of superheated steam is, of course, to give a greater thermal efficieney to the engine in which it is used and reduce the number of pounds of steam required per horse-power. The question has frequently been raised whether there is a corresponding saving in fuel. That is, will not the fact that a pound of superheated steam contains more thermal units than a pound of saturated steam require in the long run a greater expenditure of fuel per pound of steam, so that, although fewer pounds of steam are used per horse-power, it takes a greater amount of coal for a given number of pounds of water evaporated? Speaking generally, it may be asserted that with superheaters properly designed and located, and within the limit of superheat ordinarily used in marine practice-50 to 100 degrees-such tests as have been made, and such general experience as has been gained, tend to show that there is in the long run practically no increase in the fuel per pound of steam, or, in other words, there would be almost exactly the same percentage of reduction in the amount of fuel used as in the amount of steam per horse-power. It is not diffenlt to understand why this should be the case in a properly designed arrangement of superheaters. In all the cases cited, and these are the only ones for which data are available the superheaters are used with Babcock \& Wilcox boilers. As is well known, a. system of baffing is used in these boilers which causes the hot gases to cross the tubes three times on their way from the furnace to the up-take. The superheaters are placed at the passage from the first to the second pass, after the gases have crossed the tubes once before they cross the second time, so that the temperature is very much higher than in the case of the older types of superheaters, where they were placed in the up-take like a feed-water heater. The experiments which have been made on these boilers under various rates of combustion show that the temperatures where the superheater is located, when burning from 30 to 35 pounds of coal per square feet of grate, would be about 1,000 deg. Fahr., while the emperature of saturated steam of about 200 pounds is about 388 deg. Fahr. There is thus a good difference in temperature, so that a considerable degree of superheat is obtained with a moderate amount of superheating surface. There are still the second and third passes of the boiler to be acted upon by the hot gases, and the only effect is to reduce slightly the temperature of the gence the efficieney of boiler and perheater is at least as great as that of theboileralone.

The examples we have given of the navy vessels, of the "Creole" and her sister ships, and the "Wallace," with and without superheat, all show results as measured in coal, while the "Idalia" experiments give them in water. None of these experiments has the conditions absolutely ideal for determining with extreme accuracy the exact amount of gain due to superheating, because other items vary besides the extent of superheat: What practical men desire to know, however, is not results to the last decimal point, but to be reasonably sure that there is a decided gain due to superheating and this has, from the data given, been shown beyond question.

We have already mentioned one of the benefits which has been found in land service where superheated steam is used with turbines, and, obviously, thoroughly dry team, as against very moist, would be a blessing in reciprocating engines, so that this, of course, is another benefit of superheating. On board ship, where there are so many auxiliary engines scattered over a large area and many of them simple cylinders following full stroke, it can readily be seen that the use of superheated steam ought to be conducive to a great increase of economy. Unfortunately, if tests of this kind have ever been made by the Navy Department they have not been published. It now remains to mention some of the drawbacks, or rather matters which have to be attended to, if the use of superheated steam is to be entirely satisfactory. In the central stations and power houses on shore, be fore the use of superheated steam, many of the valves and fittings in the pipe lines were of cast iron. It was found that superheat of 100 degrees, or higher, caused considerable trouble, due to distortion of the cast iron fittings and inability to keep the valves tight. The general practice now is to avoid the use of brass or cast iron, and the valve bodies and fittings which come in contact with superheated steam are to be of cast steel. Valve seats are made of bronze with a large percentage of nickel or of Monel metal, which is a natural bronze of somewhat similar composition. The navy is now using Monel metal valves and seats. With these precautions, experience has shown that superheated steam up to $\mathbf{1 0 0}$ degrees can be used with great satisfaction a far as practical service is concerned, with no increased cost of repairs and with decided increase in efficiency.

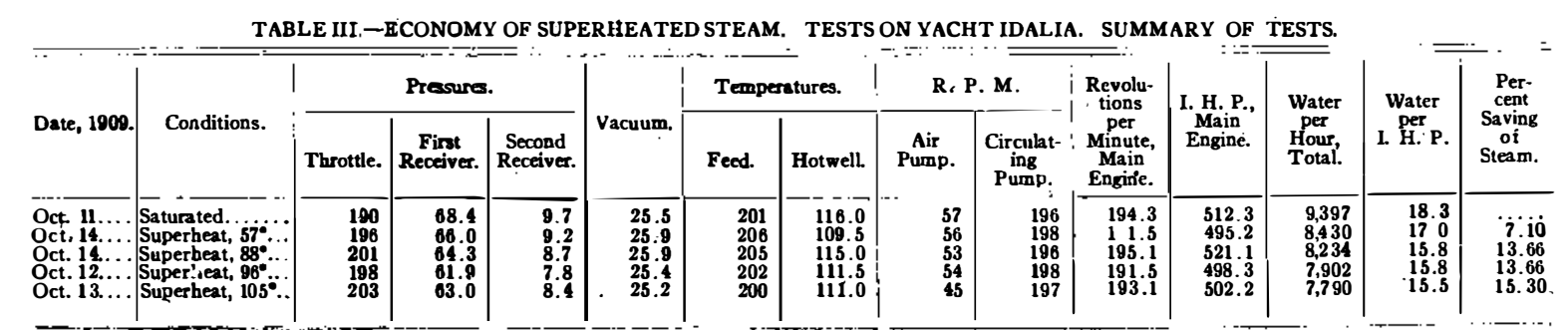




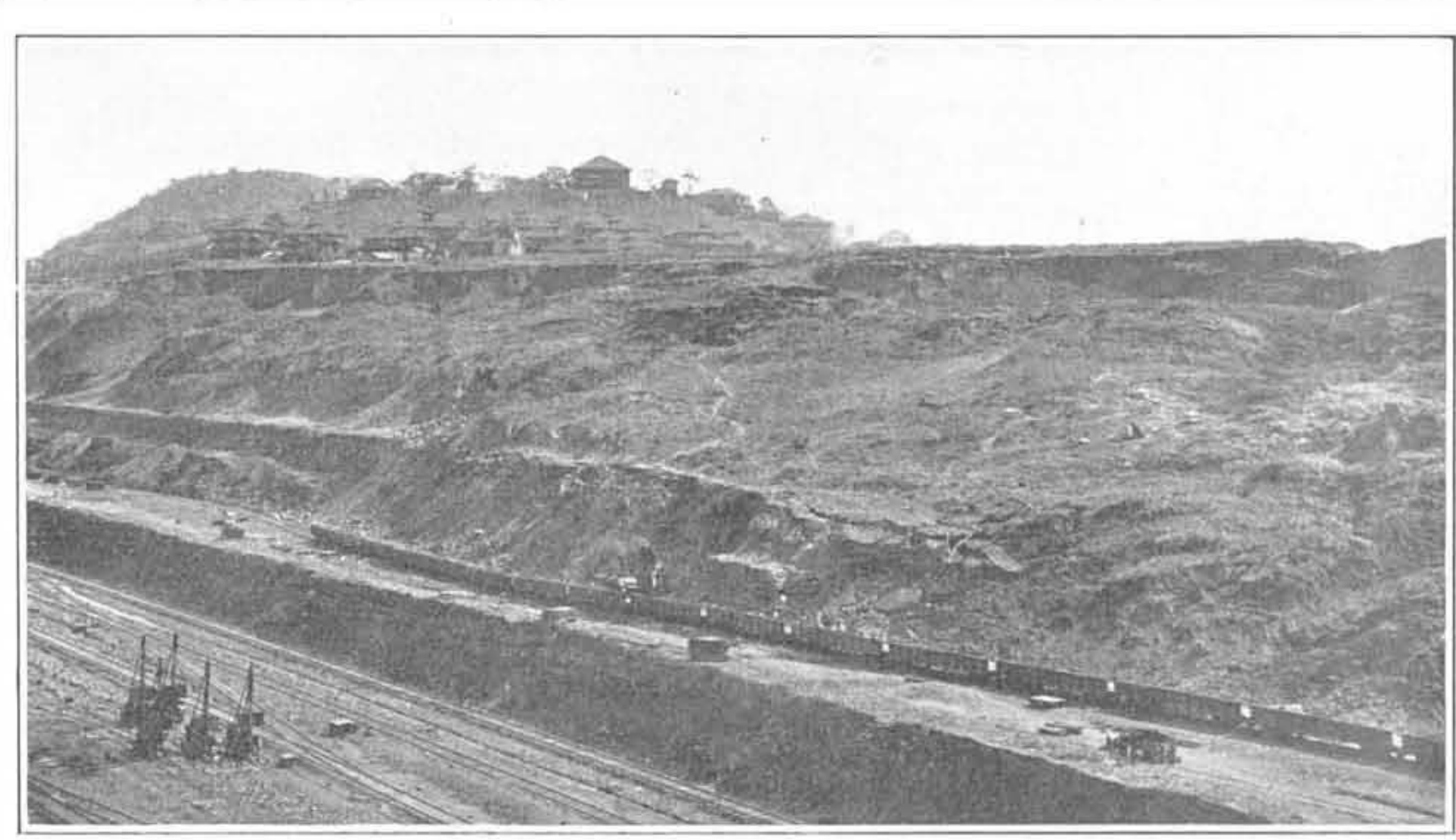

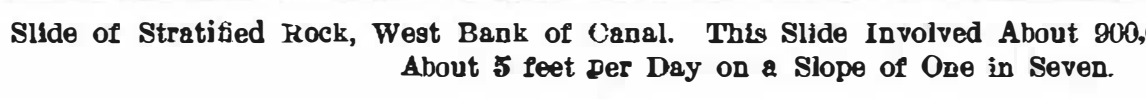

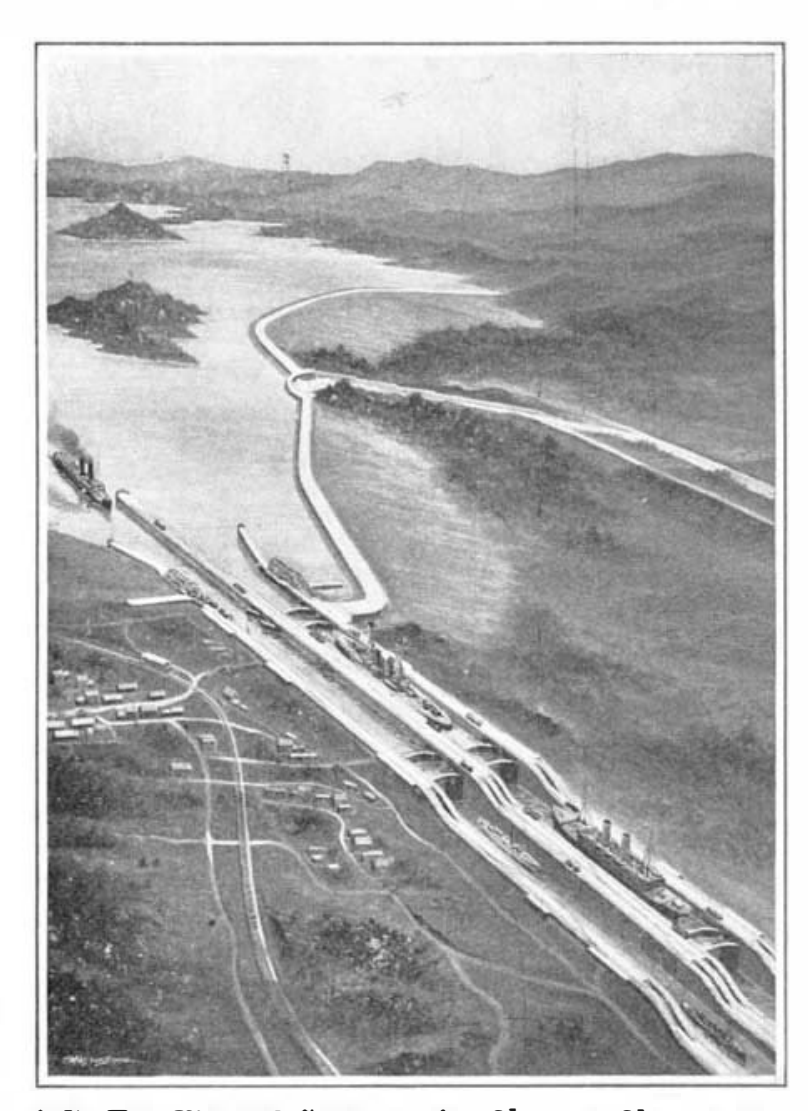

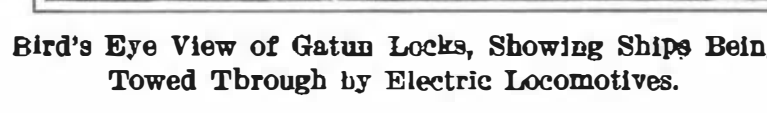

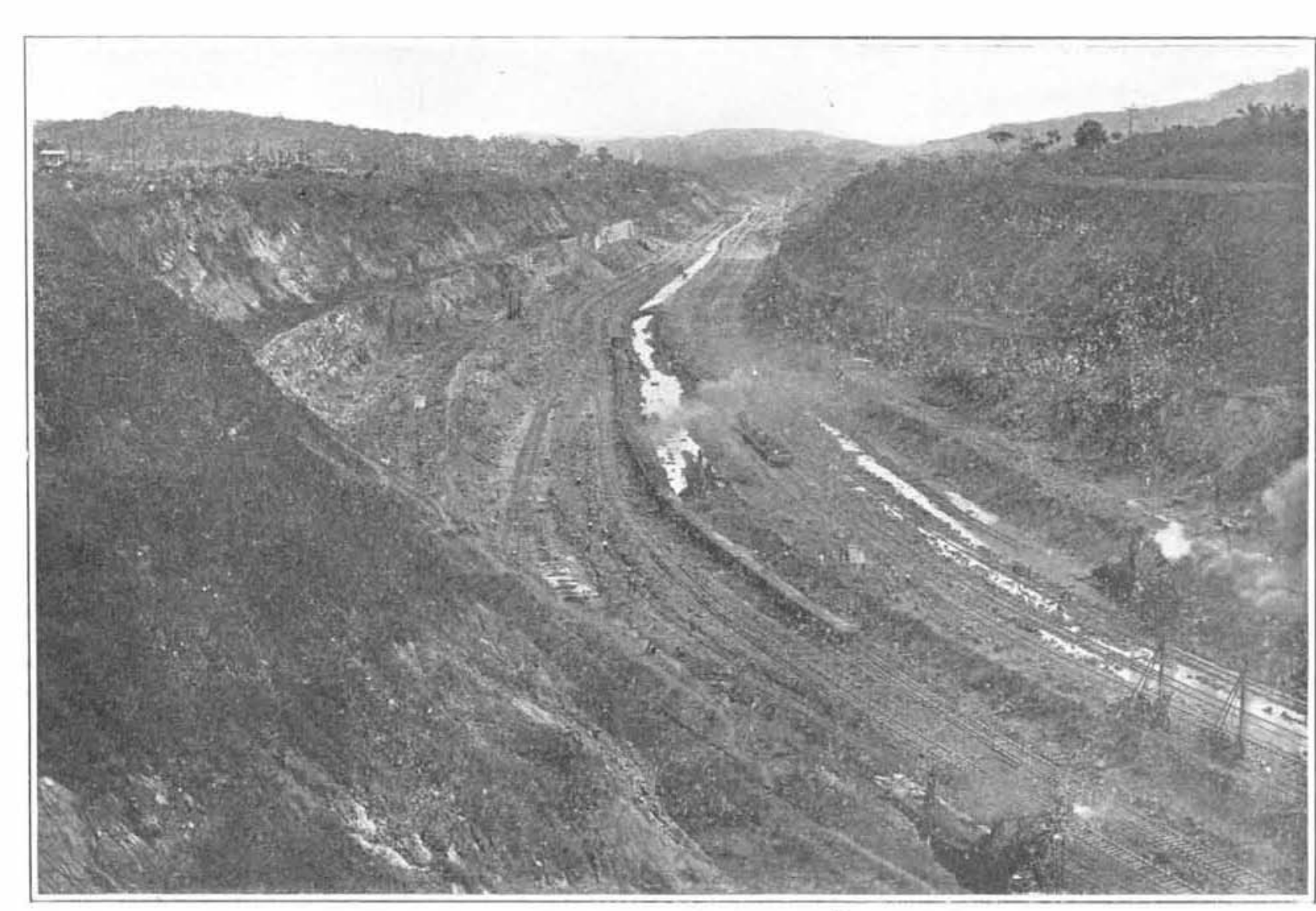

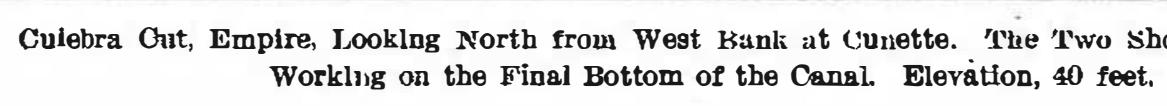

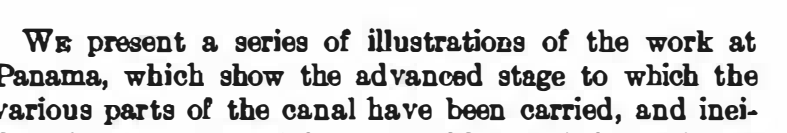

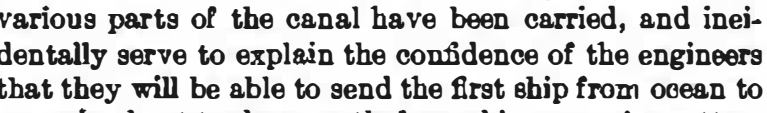

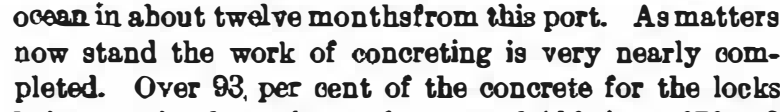

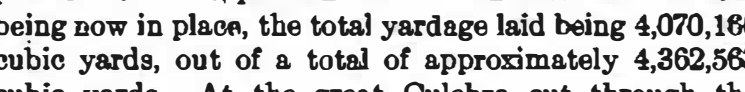

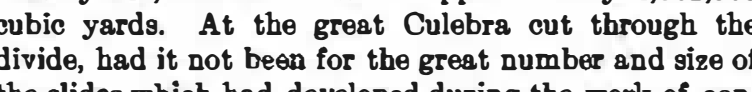

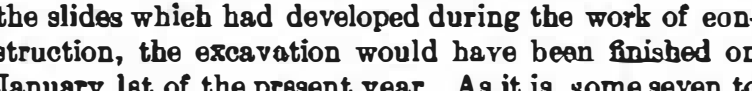

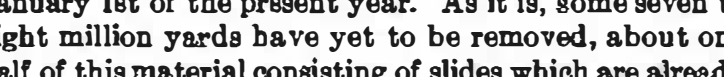

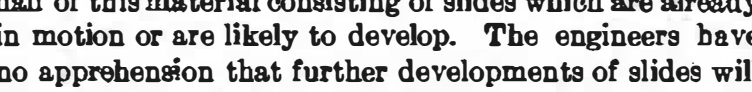

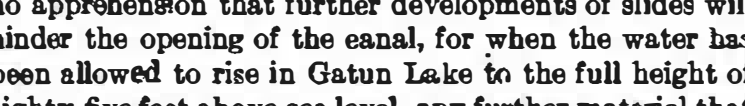

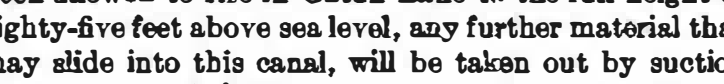

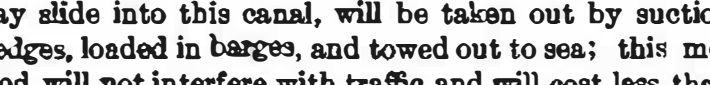

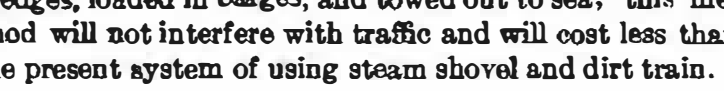

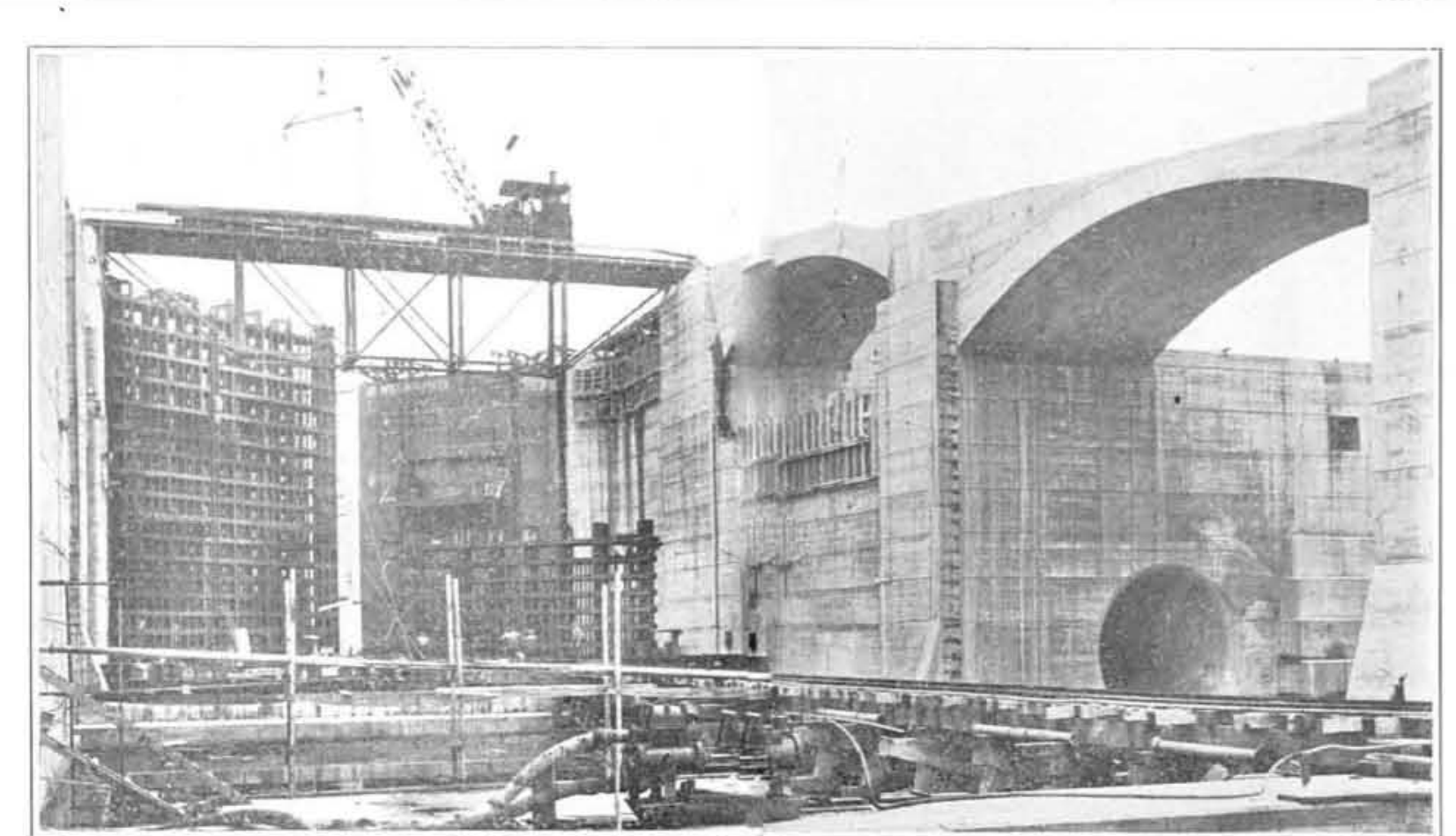

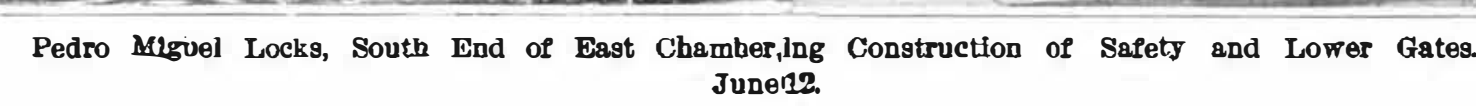

Completing the Panama Canal

A Brief Account of the Greatestgineering Work of All Time

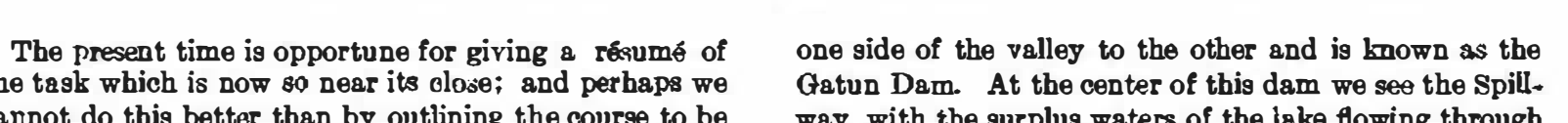

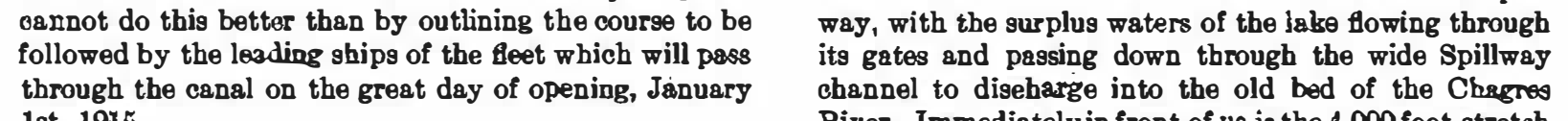

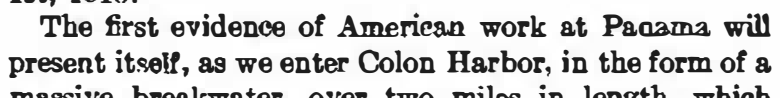

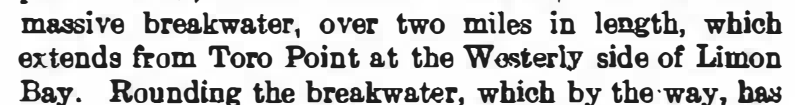

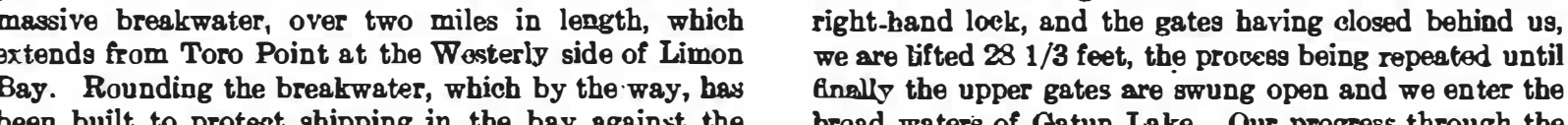

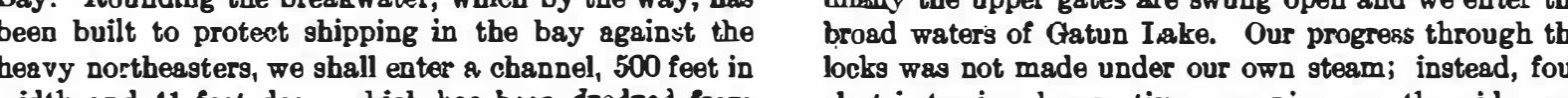

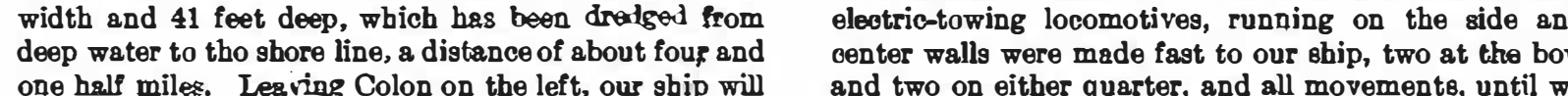

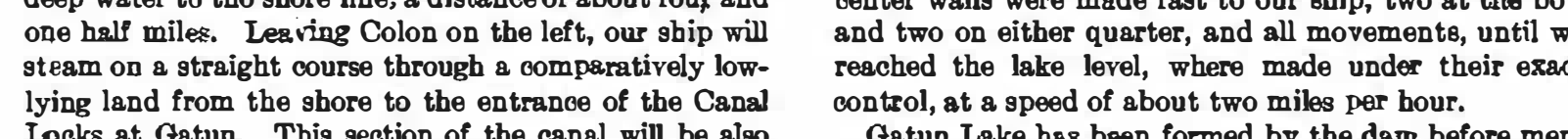

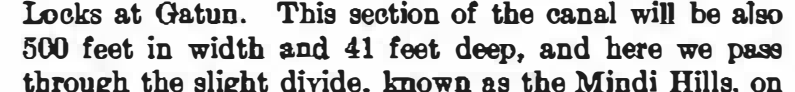

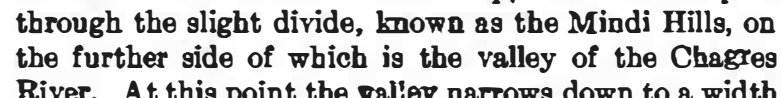

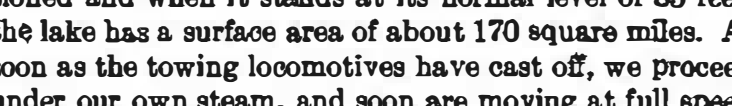

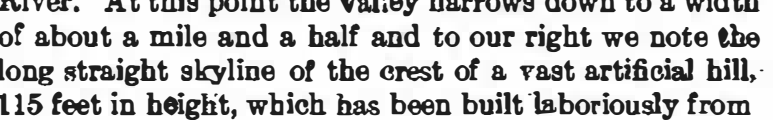

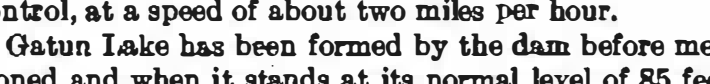

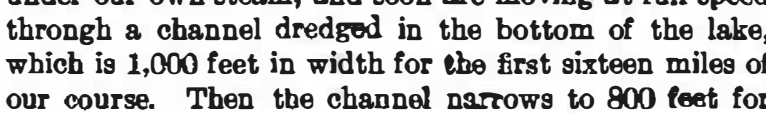

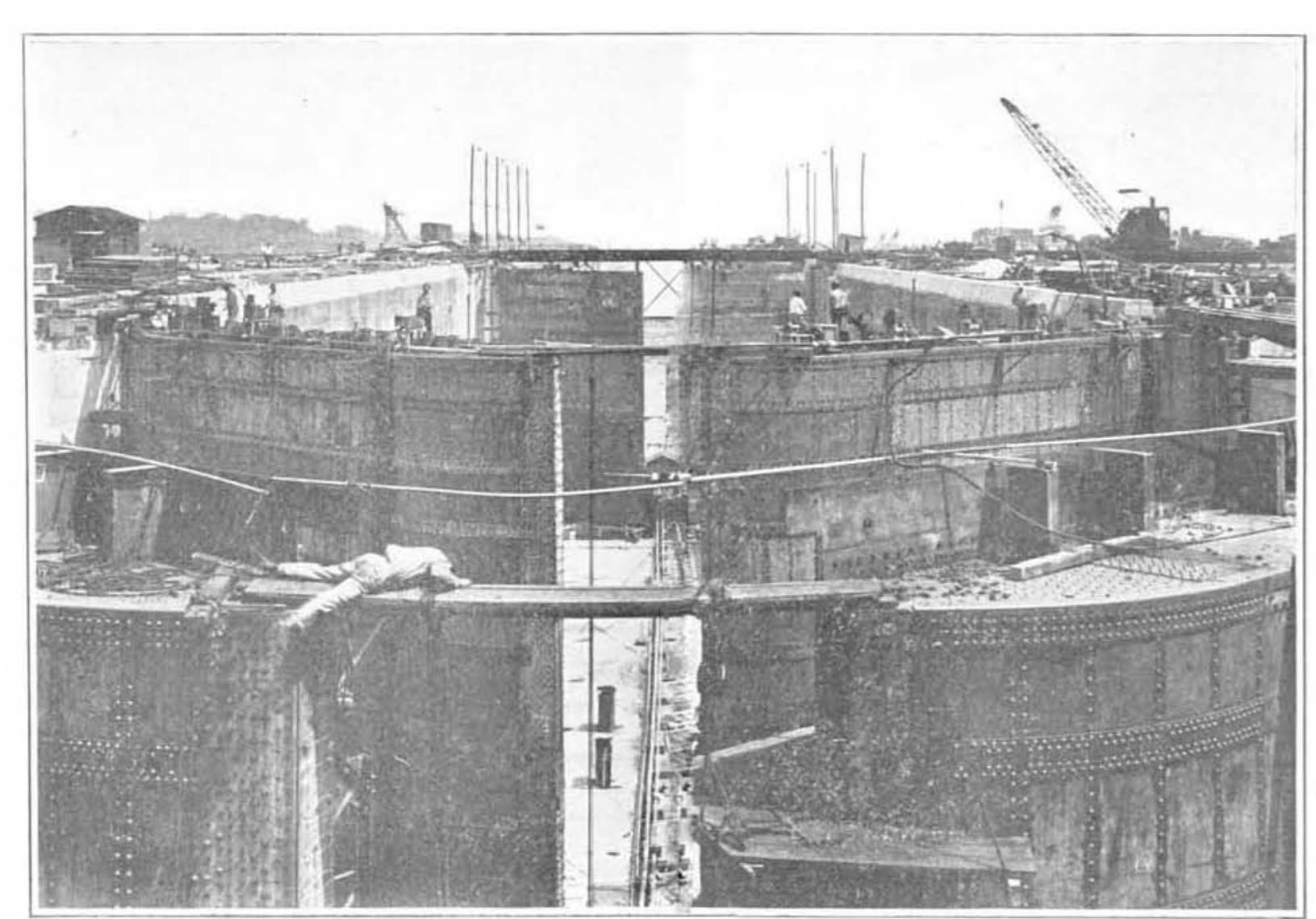

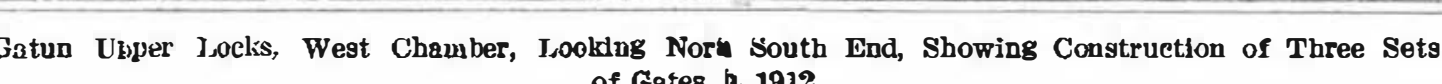

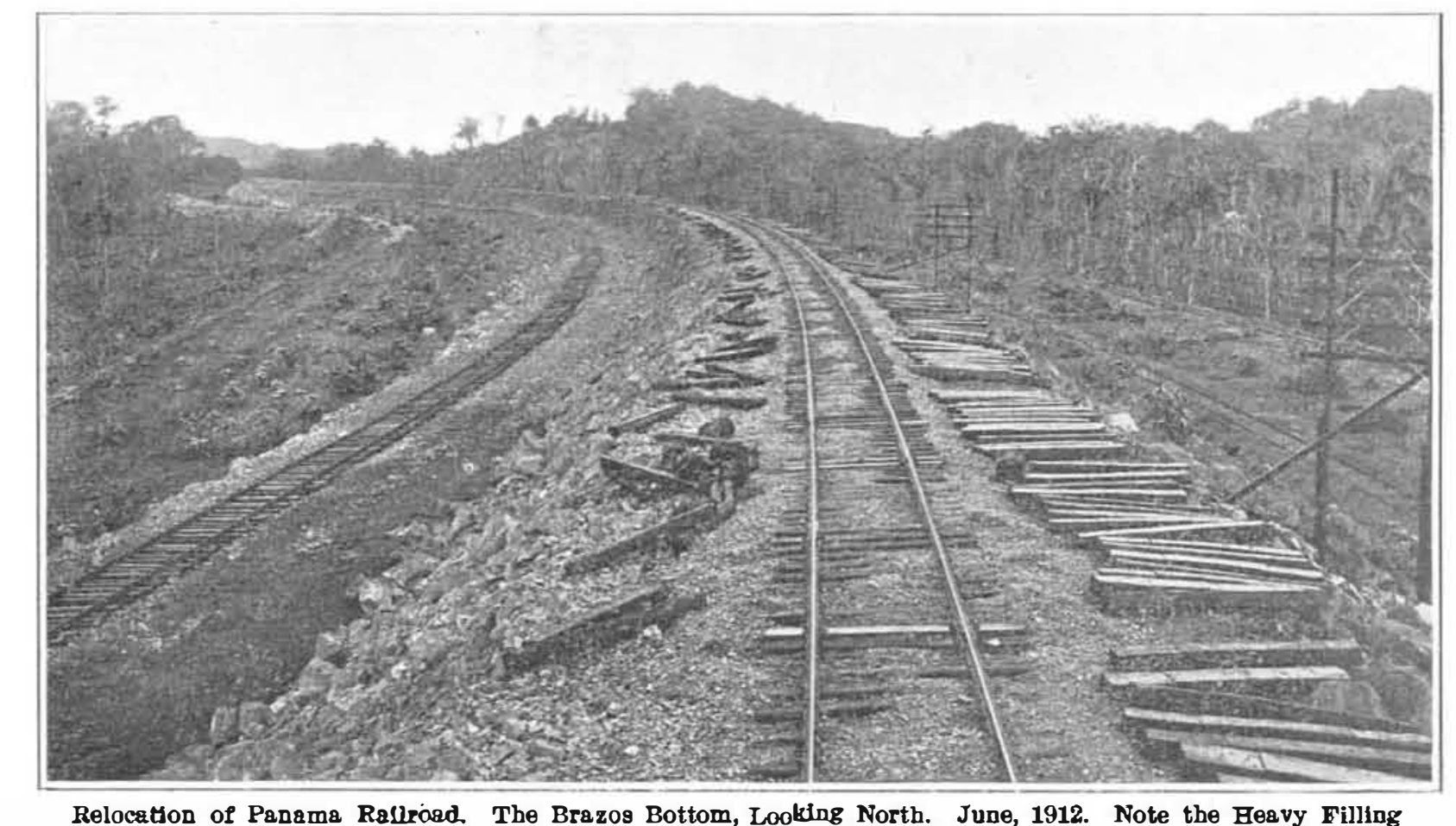

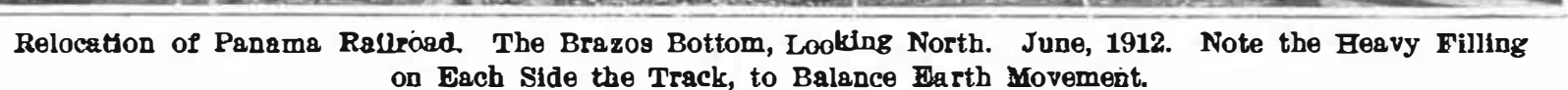

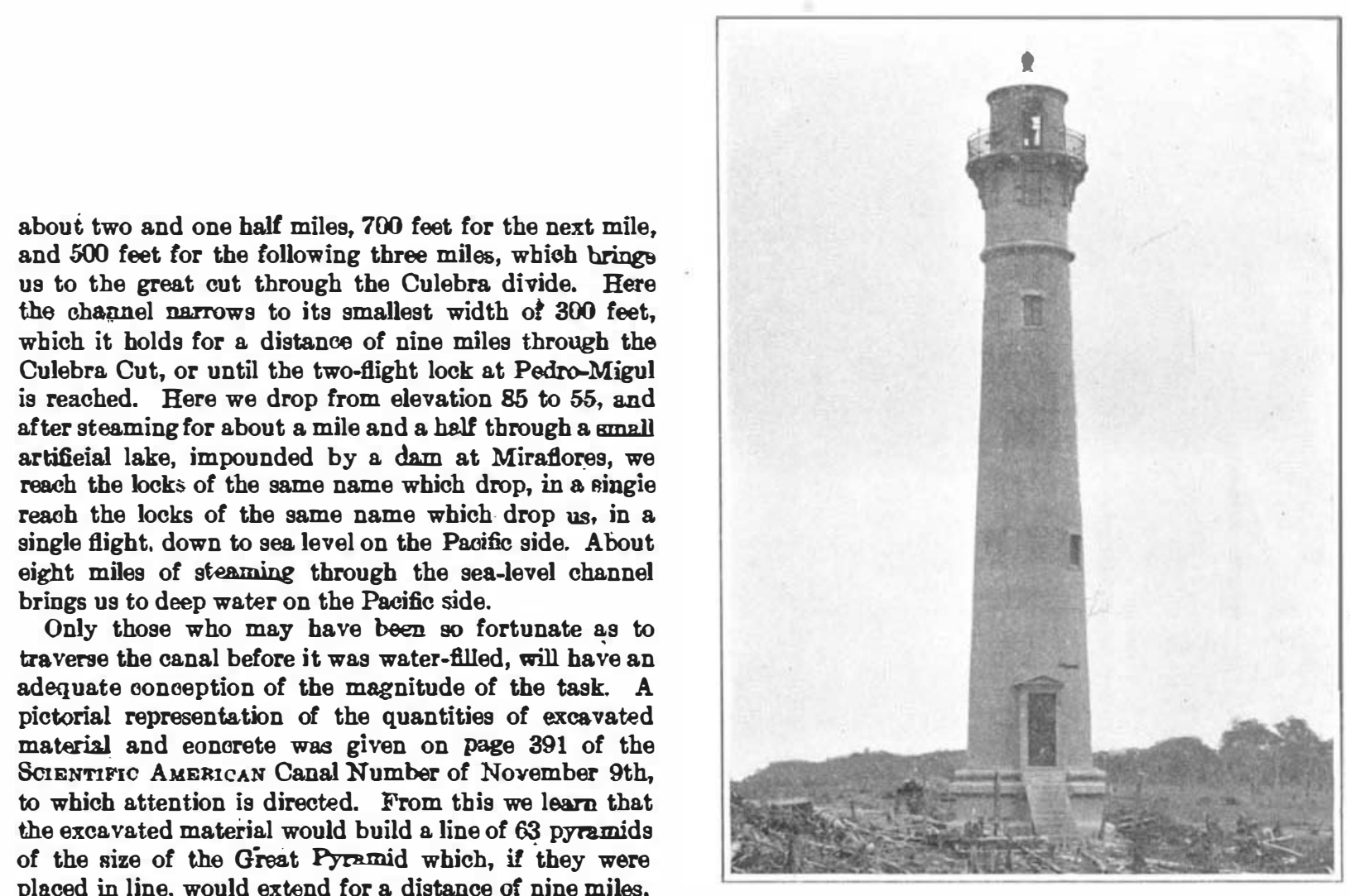

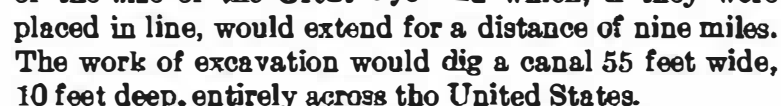

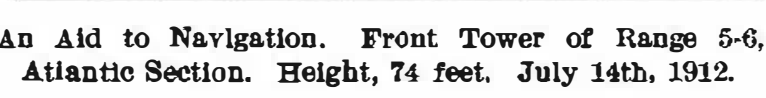

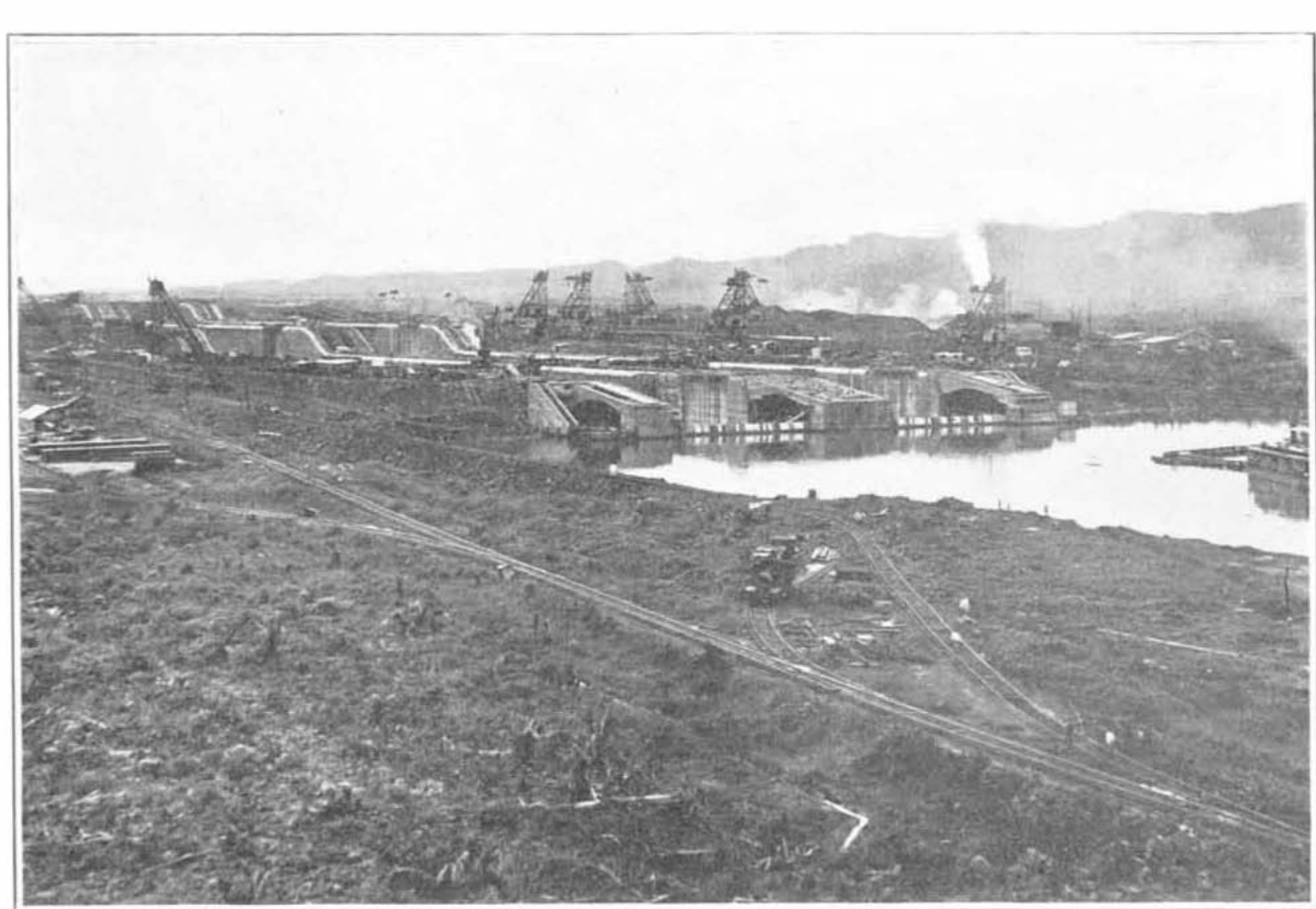

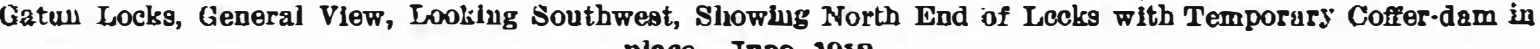

